\title{
SloR modulation of the Streptococcus mutans acid tolerance response involves the GcrR response regulator as an essential intermediary
}

Correspondence

Grace A. Spatafora

spatafor@middlebury.edu

Received 22 August 2007

Revised 20 December 2007

Accepted 21 December 2007

\author{
Daniel W. Dunning, ${ }^{1}$ Lathan W. McCall, ${ }^{1}$ William F. Powell, Jr, ${ }^{1}$ \\ W. Tristram Arscott, ${ }^{1}$ Erin M. McConocha, ${ }^{1}$ Cheryl J. McClurg, ${ }^{1}$ \\ Steven D. Goodman ${ }^{2}$ and Grace A. Spatafora ${ }^{1}$
${ }^{1}$ Department of Biology, Middlebury College, 276 Bicentennial Way, MBH354, Middlebury, VT 05753, USA CA 90089, USA \\ ${ }^{2}$ Division of Diagnostic Sciences, University of Southern California School of Dentistry, Los Angeles,
}

\begin{abstract}
Streptococcus mutans, the primary causative agent of human dental caries, grows as a biofilm on the tooth surface, where it metabolizes dietary carbohydrates and generates acid byproducts that demineralize tooth enamel. A drop in plaque $\mathrm{pH}$ stimulates an adaptive acid-tolerance response (ATR) in this oral pathogen that allows it to survive acid challenge at pHs as low as 3.0. In the present study, we describe the growth of an S. mutans mutant, GMS901, that harbours an insertion-deletion mutation in $g c r R$, a gene that encodes a transcriptional regulatory protein. The mutant is acid-sensitive and significantly compromised in its ATR relative to the UA159 wild-type progenitor strain. Consistent with these findings are the results of real-time quantitative RT-PCR (qRT-PCR) experiments that support the GcrR-regulated expression of known ATR genes, including atp $A / E$ and $f f h$. Although we observed $g c r R$ transcription that was not responsive to acidic $\mathrm{pH}$, we did note a significant increase in $g c r R$ expression when $S$. mutans cells were grown in a manganese-restricted medium. Interestingly, the results of gel mobility shift assays indicate that the S. mutans SloR metalloregulatory protein is a potential regulator of $g c r R$ by virtue of its manganese-dependent binding to the gcrR promoter region, and expression studies support the hypothesis that $s / o R$ transcription is responsive to manganese deprivation and acidic $\mathrm{pH}$.

Taking these results together, we propose that SloR-Mn modulates $S$. mutans gcrR expression as part of a general stress response, and that GcrR acts downstream of SloR to control the ATR.
\end{abstract}

\section{INTRODUCTION}

Streptococcus mutans is the principal causative agent of human dental caries, affecting populations in both developed and developing nations worldwide (Smith, 2001). It colonizes the oral cavity upon adhering to the dentition, where it forms biofilm communities (Cotter \& Hill, 2003). Within the plaque biofilm, S. mutans metabolizes dietary carbohydrates and generates lactic acid as a byproduct. Plaque and its associated diffusion barrier promote the accumulation of organic acids at the tooth surface that, in turn, demineralize tooth enamel and mark the onset of dental decay (Loesche, 1986). Despite improvements in oral hygiene, the implementation of

Abbreviations: ATR, acid-tolerance response; Ct, threshold cycle; MBP, maltose binding protein; qRT-PCR, quantitative RT-PCR.

The array data discussed in this paper have been deposited in the NCBI Gene Expression Omnibus (GEO; http://www.ncbi.nlm.nih.gov/geo/) and are accessible through GEO series accession number GSE10215. education programmes, water fluoridation and commercialized sugar substitutes, the caries pandemic persists. In the United States alone, the cost of dental care continues to exceed $\$ 70$ billion a year, and adults lose more than 164 million work hours annually to complications associated with active carious lesions (US Department of Health and Human Services, 2003).

S. mutans is aciduric in the plaque environment owing to the induction of its acid-tolerance response (ATR). The ATR allows cells that are exposed to a sublethal drop in $\mathrm{pH}$ to modulate genes whose products allow $S$. mutans to survive in acidic conditions at a $\mathrm{pH}$ as low as 3.0-4.0 (Cotter \& Hill, 2003; Foster \& Hall, 1990; Jensen et al., 1982; Len et al., 2004a; Nascimento et al., 2004). To date, a number of genes that contribute to the $S$. mutans ATR have been identified, including those involved in membrane composition, proton extrusion and DNA repair (Fozo \& Quivey, 2004; Griswold et al., 2006; Hamilton \& Svensater, 1998; Hanna et al., 2001; Jayaraman et al., 1997; Kuhnert 
et al., 2004; Lemos et al., 2001; Len et al., 2004b; Li et al., 2001a, b). Since the ATR contributes to the ability of $S$. mutans to adapt to and compete in the plaque environment, an improved understanding of this response and its regulation could prove paramount to the development of therapeutics that target the $S$. mutans caries-forming process.

Previously, we reported on a GcrR (also designated TarC) orphan response regulator in $S$. mutans that promotes sucrose-dependent adherence and cariogenesis (Idone et al., 2003). Specifically, we demonstrated aberrant biofilm formation for a UA130-derived $g c r R$ mutant (GMS900) and confirmed a decreased incidence of dental caries when this mutant was used to mono-infect a germ-free rat model. We also observed that the expression of $g t f D$ and $g b p C$, known to be involved in S. mutans sucrose-dependent adherence, was derepressed in GMS900 relative to the UA130 progenitor strain. From these studies, we concluded that GcrR plays a significant role in S. mutans colonization of the tooth surface and subsequent pathogenesis.

In the present study, in silico analysis of the S. mutans GcrR sequence revealed that it shares significant amino acid identity with response regulators from Streptococcus pyogenes (CovRS), Enterococcus faecalis (EtaRS), and Listeria monocytogenes (LisRK). Like S. mutans, these bacterial pathogens can tolerate exposure to acidic conditions during the progression of host infection by mounting an appropriate ATR (Dalton \& Scott, 2004; Ferreira et al., 2001; Flahaut et al., 1996a), and reports have described mutants with lesions in covRS, etaRS or lisRK as more sensitive to acid than their wild-type progenitors (Cotter et al., 1999; Dalton \& Scott, 2004; Teng et al., 2002). In light of these studies and given the association of $S$. mutans acid production with carbohydrate metabolism, we propose a putative role for the GcrR response regulator in S. mutans aciduricity and acid tolerance. To this end, we generated a $g c r R$ insertion-deletion mutation in the $S$. mutans UA159 chromosome, for which the genome sequence is known, and compared the acid sensitivity and ATR of the resulting GMS901 mutant with that of its UA159 progenitor and the previously described isogenic SloR-knockout mutant, GMS584 (Rolerson et al., 2006). SloR is an iron- and manganese-dependent metalloregulatory protein in S. mutans that modulates the expression of multiple genes, some of which contribute to virulence (Rolerson et al., 2006). Herein, we present evidence to support SloR regulation of the $S$. mutans ATR that involves GcrR as an essential intermediary.

\section{METHODS}

Bacterial strains, plasmids, and growth conditions. The bacterial strains and plasmids used in this study are listed in Table 1. Escherichia coli was grown as overnight cultures at $37{ }^{\circ} \mathrm{C}$ in Luria broth (Difco) with gentle aeration, or, when appropriate, on Luria agar plates with erythromycin or chloramphenicol at final concentrations of 300 and $25 \mu \mathrm{g} \mathrm{m} \mathrm{m}^{-1}$, respectively. S. mutans UA159 was grown routinely as an overnight standing culture at $37{ }^{\circ} \mathrm{C}$ and $5 \%$ $\mathrm{CO}_{2}$ in Todd-Hewitt broth supplemented with $0.3 \%$ yeast extract (THYE). Erythromycin $\left(10 \mu \mathrm{g} \mathrm{ml}^{-1}\right)$ was added to the growth medium to maintain selective pressure for the S. mutans GMS584, GMS901, GMS902-3 and citM $^{-}$strains. To assess S. mutans acid sensitivity in growth determination assays, cells were grown in THYE adjusted to $\mathrm{pH} 7.5$ or $\mathrm{pH} 5.0$ with $2 \mathrm{M}$ dibasic potassium phosphate and $1 \mathrm{M}$ potassium citrate, as previously described (Hanna et al., 2001). The THYE pH 7.5 medium was further supplemented with $0.1 \mathrm{M}$ morpholinepropanesulfonic acid to maintain neutral $\mathrm{pH}$ conditions during $S$. mutans growth and acidogenesis. To monitor S. mutans gene expression at physiological and acid $\mathrm{pH}$ in real-time quantitative RT-PCR (qRT-PCR) experiments, cultures grown overnight in THYE pH 7.5 were pelleted at 7000 r.p.m. in a Sorvall SS-34 rotor for $10 \mathrm{~min}$ at $4{ }^{\circ} \mathrm{C}$ and then exposed to either THYE $\mathrm{pH} 7.5$ (unadapted) or $\mathrm{pH} 5.0$ (adapted) for $2 \mathrm{~h}$ prior to RNA isolation. For expression profiling under manganese-depleted versus -replete conditions, $S$. mutans cells were grown to mid-exponential phase in a semi-defined minimal medium (SDM) (Li et al., 2002) that had been Chelex-treated and supplemented with ferric citrate, magnesium chloride and 0.1 or $10 \mu \mathrm{M}$ manganese chloride, as described elsewhere (Rolerson et al., 2006), for which the metal ion content was confirmed by inductively coupled argon plasma analysis.

Table 1. Bacterial strains and plasmids used in this study

\begin{tabular}{|c|c|c|}
\hline Strain or plasmid & Genotype or phenotype & Source or reference \\
\hline \multicolumn{3}{|l|}{ S. mutans strains } \\
\hline UA159 & Wild-type, serotype $c$ & ATTC 700610 \\
\hline GMS901 & UA159-derived, $g c r R$-deficient, $\mathrm{Em}^{\mathrm{R}}$ & This work \\
\hline GMS902-3 & $\begin{array}{l}\text { GMS901-derived, } \mathrm{Em}^{\mathrm{R}}, g c r R \text { mutation complemented in trans with cloned } g c r R \text { on } \\
\text { plasmid pDD-1 }\end{array}$ & This work \\
\hline \multicolumn{3}{|l|}{ E. coli strains } \\
\hline DH5 $\alpha$ & $\begin{array}{l}\text { GC5 chemically competent cells } \mathrm{F}^{-} \phi 80 \text { lacZ } \mathrm{M} 15 \Delta[\text { lacZYA-argF]U169 recA1 endA1 } \\
\text { hsdR17, phoA supE44 thi-1 gyrA96 relA1 } \lambda^{-} \text {, tonA }\end{array}$ & Gene Choice \\
\hline \multicolumn{3}{|c|}{ 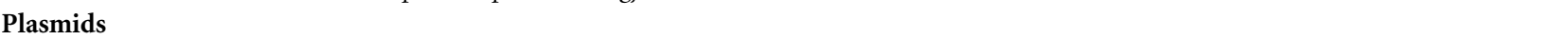 } \\
\hline pVA838 & S. mutans shuttle plasmid, $\mathrm{Em}^{\mathrm{R}}, \mathrm{Cm}^{\mathrm{R}}$ & Macrina et al. (1982) \\
\hline pDD-1 & pVA838 with cloned $1.4 \mathrm{~kb} g c r R$ gene and promoter region & This work \\
\hline
\end{tabular}


Construction of an S. mutans gcrR knockout mutant. PCR ligation mutagenesis (Lau et al., 2002) was used to disrupt the $\mathrm{gcrR}$ coding sequence of the $S$. mutans UA159 chromosome, as illustrated in Fig. 1. Primers were designed using MacVector (v. 7.2.2) software and purchased from Sigma Genosys. PCR amplicons were generated in a $40 \mu \mathrm{l}$ final reaction volume using primers $g c r R \_\mathrm{P} 1$ and $g c r R \_\mathrm{P} 2$, gcrR_P3 and gcrR_P4, and erm.Asc1.F and ermFse1.R (Table 2). The reaction mixtures were placed in an automated thermal cycler (Hybaid) that was programmed to run one $10 \mathrm{~min}$ cycle of denaturation at $94{ }^{\circ} \mathrm{C}$ followed by 35 cycles of denaturation at $94{ }^{\circ} \mathrm{C}$ for $1 \mathrm{~min}$, primer annealing at the optimal temperature (Table 2) for $2 \mathrm{~min}$, and extension at $72{ }^{\circ} \mathrm{C}$ for $3 \mathrm{~min}$, followed by a final extension at $72{ }^{\circ} \mathrm{C}$ for $10 \mathrm{~min}$. The resulting P1/P2 and P3/P4 PCR amplicons were purified with a PCR Purification Kit (Qiagen), digested with AscI and/or FseI (New England Biolabs), and ligated to the $860 \mathrm{bp}$ ermAM cassette for $18 \mathrm{~h}$ at $16{ }^{\circ} \mathrm{C}$ in each of two separate reactions and in the presence of T4 DNA ligase. The resulting ligation mixture was used as a template in another round of amplification with the P1 and $\mathrm{P} 4$ primer set to generate a $1295 \mathrm{bp}$ tripartite ligation end product. $S$. mutans UA159 cells were transformed with the final ligation mixture in the presence of competence-stimulating peptide, as described elsewhere (Lau et al., 2002; Li et al., 2001b). Transformed colonies were selected on THYE-agar plates with $10 \mu \mathrm{g}$ erythromycin $\mathrm{ml}^{-1}$ after overnight incubation at $37{ }^{\circ} \mathrm{C}$ and $5 \% \mathrm{CO}_{2}$. Chromosomal DNA was isolated from selected transformants and the UA159 progenitor according to established protocols (Sambrook et al., 1989) so that subsequent PCR and nucleotide sequencing could confirm insertion of the $860 \mathrm{bp}$ ermAM cassette at the desired $g c r R$ locus. Purified amplicons were sequenced across the $g c r R-e r m A M$ junctions with the existing $g c r R \_P 1$ and gcrR_P4 primer set on a Perkin-Elmer ABI Prism 377 DNA sequencer using dye-terminator chemistry.

Monitoring S. mutans aciduricity in growth determination assays. To determine the sensitivity of $S$. mutans cells to growth at $\mathrm{pH}$ 5.0, overnight cultures of S. mutans UA159, GMS901, GMS902-3 and GMS584 were diluted 1:10 in fresh THYE pH 7.5 medium and monitored for growth with a Spectronic Genesys 2 spectrophotometer. The cells were harvested at mid-exponential phase $\left(\mathrm{OD}_{600}=0.4-0.6\right)$ and the culture densities were standardized to within 0.05 OD units with fresh THYE. The resulting cell suspensions were diluted $1: 20$ into fresh THYE $\mathrm{pH} 7.5$ or $\mathrm{pH} 5.0$ and distributed in $420 \mu \mathrm{l}$ aliquots into the wells of a 100 -well honeycomb microtitre plate (Growth Curves USA) in triplicate. The cells were incubated for $48 \mathrm{~h}$ at $37^{\circ} \mathrm{C}$ in a Bioscreen C Microbiology Reader (Labsystems), and $\mathrm{OD}_{600}$ measurements were obtained every $15 \mathrm{~min}$ with gentle agitation preceding each reading. Doubling times from each of three independent experiments were determined for cells in exponential phase and at points corresponding to when the rate of growth was fastest. The viability of $S$. mutans stationary-phase cells at $\mathrm{pH} 5.0$ was determined by plating cells from the $t=24 \mathrm{~h}$ time point onto THYE agar so that c.f.u. could be enumerated.

Monitoring S. mutans acid tolerance in acid-challenge experiments. To assess the $S$. mutans ATR, the established protocol of Hanna et al. (2001) was followed. Briefly, UA159, GMS901, GMS902-3 and GMS584 mid-exponential-phase cells were grown in THYE and harvested by centrifugation as described above, followed by resuspension in THYE pH 7.5 (unadapted) or pH 5.0 (adapted) and cellular deaggregation by successive passages through a 26 gauge, $5 / 8$ inches $(15.9 \mathrm{~mm})$ length needle. The cell suspensions were then incubated for $2 \mathrm{~h}$ at $37{ }^{\circ} \mathrm{C}$ and $5 \% \mathrm{CO}_{2}$, during which no appreciable growth occurred as determined by spectrophotometry. Following incubation, the cells were pelleted and resuspended in THYE pH 3.5 for 45, 90 or $180 \mathrm{~min}$ before being passed once again through a fine-gauge needle and spread-plated onto THYE agar. The ATR was assessed for both adapted and unadapted cultures by viable plate counting, with survival at each time point expressed as a percentage of viable cells (in c.f.u. $\mathrm{ml}^{-1}$ ) that were present in the original pH 5.0 cell suspension immediately after exposure to the lethal $\mathrm{pH}$ of $3.5(t=0)$.

Complementation experiments. A $1.4 \mathrm{~kb}$ amplicon containing the wild-type $g c r R$ gene and promoter region was PCR-amplified with primers $g c r R$. PvuII.F and $g c r R . E c o$ RI.R (Table 2), digested with EcoRI and PvuII according to the recommendations of the supplier (Promega), and cloned into the EcoRI/PvuII site of the replicative shuttle plasmid pVA838 (Table 1). The resulting recombinant was introduced into chemically competent E. coli DH5 $\alpha$ (Gene Choice), after which transformants were screened for erythromycin resistance and chloramphenicol sensitivity, and processed for plasmid DNA isolation on miniprep spin columns (Qiagen). Recombinant plasmids

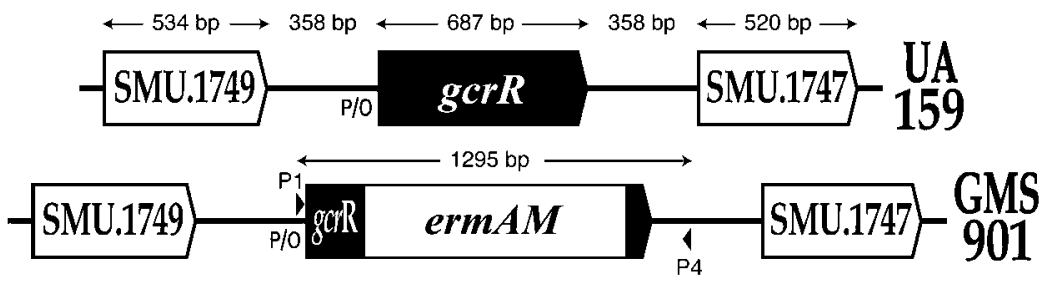

Fig. 1. Organization of the gcrR locus in $S$. mutans UA159 and GMS901. Shown is a map of the $g c r R$ locus on the $S$. mutans UA159 and GMS901 chromosomes. The gcrR gene is flanked by $\sim 350 \mathrm{bp}$ of noncoding DNA upstream and downstream, and is not co-transcribed with a cognate histidine kinase. A search of the Los Alamos Oral Pathogen Sequence database (http://www.oralgen.lanl.gov) revealed the gene products of SMU.1747 and SMU.1749 to be conserved hypothetical proteins of unknown function. We used a 1295 bp PCR construct to disrupt the $S$. mutans gcrR coding sequence on the UA159 chromosome. Details of the mutagenesis procedure are described in Methods. The resulting allelic replacement was confirmed by nucleotide sequencing with primers $\mathrm{P} 1$ and $\mathrm{P} 4$ (indicated by arrowheads), and the mutant was designated GMS901. 
Table 2. Primers used in this study

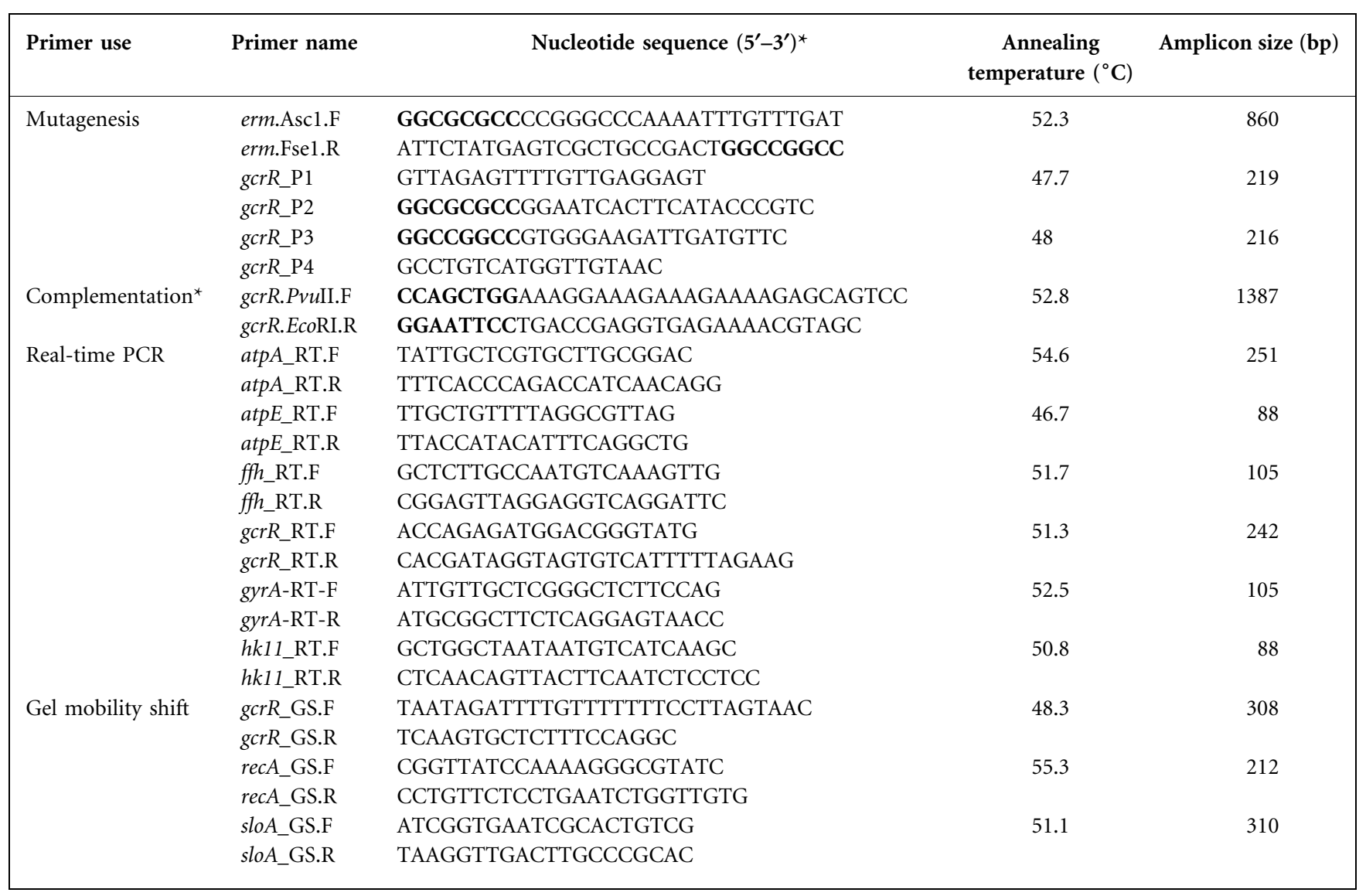

${ }^{*}$ Restriction sites are shown in bold type.

containing the $1.4 \mathrm{~kb}$ insert were confirmed by HindIII restriction mapping and PCR amplification with the $g c r R \_$RT.F and $g c r R \_$RT.R primer set (Table 2). The confirmed gcrR-containing plasmid, designated pDD1, was introduced into S. mutans GMS901 by CSPinduced transformation, as described previously (Li et al., 2001b), and erythromycin-resistant transformants were screened for 'loss' of the GMS901 aggregation phenotype upon overnight growth in THYE broth. Selected strains were processed for plasmid DNA isolation according to the rapid screening procedure of Leblanc \& Lee (1979), and $S$. mutans clones that tested positive for $\mathrm{pDD}-1$ were designated GMS902-3 and analysed for complementation of the ATR defect in growth-determination and acid-challenge experiments.

RNA isolation. Mid-exponential-phase cultures $\left(\mathrm{OD}_{600}=0.5\right)$ of $S$. mutans wild-type and mutant strains were harvested by centrifugation as described above and resuspended in $3 \mathrm{ml}$ TRI Reagent (Ambion). The cell slurry was mechanically disrupted for $40 \mathrm{~s}$ at $4{ }^{\circ} \mathrm{C}$ in a Bio 101 FastPrep machine in the presence of zirconium beads, and the aqueous phase, containing nucleic acid, was ethanol-precipitated. The DNA/ RNA pellets were washed in $70 \%$ ethanol and finally resuspended in nuclease-free water prior to DNase I treatment on an RNeasy column (Qiagen) according to the recommendations of the supplier. RNA integrity was assessed by ethidium bromide staining of the $23 \mathrm{~S}$ and $16 \mathrm{~S}$ rRNA subunits on a $1 \%$ agarose gel, and quantified spectrophotometrically at $A_{260}$ for concentration and at $A_{260} / A_{280}$ for purity.

Monitoring gene expression in real-time qRT-PCR experiments. Total intact RNA obtained from $S$. mutans UA159,
GMS584 and GMS901 was reverse-transcribed into cDNA using a First Strand cDNA Synthesis kit (MBI Fermentas), according to the manufacturer's instructions. Reactions containing no RNA template (NTC) or no reverse transcriptase (RT-) served as controls. The resulting cDNA (10 ng) was used as a template along with $150 \mathrm{nM}$ primers (Table 2) for amplification in a Cepheid Smart Cycler using SYBR Green I as the intercalating dye (Invitrogen). The RT - controls were used as a template with the same primer sets to confirm the absence of contaminating chromosomal DNA in the RNA preparations. The cDNAs were denatured at $95{ }^{\circ} \mathrm{C}$ for $15 \mathrm{~min}$, followed by 40 cycles of denaturation at $95{ }^{\circ} \mathrm{C}$ for $15 \mathrm{~s}$, primer annealing at optimal temperature (Table 2) for $30 \mathrm{~s}$, and primer extension at $72{ }^{\circ} \mathrm{C}$ for $30 \mathrm{~s}$. The expression of $\mathrm{gcrR}$ in UA159 versus GMS584 was normalized to that of $h k 11$, which we determined did not change in these strains when grown under the experimental test conditions. For UA159 and GMS901 expression profiling at different $\mathrm{pH}$ and manganese concentrations, we used gyrA for normalization, the expression of which we determined was invariant under the test conditions. Standard curves for each primer set were derived from an S. mutans genomic DNA dilution series and subsequently used to calculate DNA copy number. Threshold cycle $(\mathrm{Ct})$ values were assigned a cycle number at which the second derivative of the fluorescence curve was at its maximum.

Gel mobility shift assays. Gel mobility shift assays were performed according to a modification of the protocol of Tao et al. (1992) with a SloR-MBP (maltose binding protein) fusion protein that we had isolated previously (Rolerson et al., 2006). The primers used to 
PCR-amplify the promoter regions of the S. mutans gcrR, recA and sloABC genes are listed in Table 2. The purified PCR products (Qiagen) were quantified spectrophotometrically before end-labelling in separate reaction mixtures containing $10 \mu \mathrm{Ci}(370 \mathrm{kBq})\left[\gamma^{32} \mathrm{P}\right] \mathrm{ATP}$ (Perkin Elmer) and $10 \mathrm{U}$ T4 polynucleotide kinase (New England Biolabs). Reaction mixtures were incubated for $30 \mathrm{~min}$ at $37{ }^{\circ} \mathrm{C}$ and then for $20 \mathrm{~min}$ at $70{ }^{\circ} \mathrm{C}$ before the final sample volume was adjusted to $50 \mu \mathrm{l}$ with sterile distilled $\mathrm{H}_{2} \mathrm{O}$. Unincorporated radiolabel was removed by passage through a G-25 Sepharose column (Roche Applied Science). Binding reactions were prepared in total volumes of $16 \mu \mathrm{l}$ containing $1 \mu \mathrm{l}(\sim 17 \mathrm{ng})$ end-labelled DNA, up to $8.5 \mu \mathrm{M}$ SloR-MBP fusion protein or MBP, and $3.2 \mu \mathrm{l} 5 \times$ binding buffer (42 mM NaH${ }_{2} \mathrm{PO}_{4}, 58 \mathrm{mM} \mathrm{Na} \mathrm{HPO}_{4}, 250 \mathrm{mM} \mathrm{NaCl}, 25 \mathrm{mM}$ $\mathrm{MgCl}_{2}, 50 \mu \mathrm{g} \mathrm{BSA} \mathrm{ml}{ }^{-1}, 1 \mathrm{mg}$ sonicated salmon sperm DNA and $50 \%, \mathrm{v} / \mathrm{v}$, sterile glycerol). The $5 \times$ binding buffer was supplemented, when appropriate, with $\mathrm{MnCl}_{2}$ to a final concentration of $150 \mathrm{mM}$ to facilitate SloR-DNA binding. To determine the metal ion dependency of SloR binding, an EDTA metal ion chelator was added to the reaction mixtures at a final concentration of $15 \mathrm{mM}$. In an attempt to restore the SloR-DNA binding phenotype, $14 \mu \mathrm{l} 0.1 \mathrm{M} \mathrm{MnCl}_{2}$ stock solution was added to EDTA-containing samples. A 310 bp amplicon that harbours the $\operatorname{slo} A B C$ promoter region was used as a positive control in these experiments, and a $212 \mathrm{bp}$ amplicon that harbours the $S$. mutans recA promoter region was used as a negative control. Cold gcrR amplicon (308 bp) was included as competitor DNA in certain reaction mixtures to confirm specificity of SloR-MBP binding to the gcrR promoter region. All protein-DNA reaction mixtures were incubated for $20 \mathrm{~min}$ at room temperature before they were resolved on $18 \%$ non-denaturing polyacrylamide gels for $1 \mathrm{~h}$ at $300 \mathrm{~V}$. The gels were processed for autoradiography and exposed to Kodak BIOMAX film for $24 \mathrm{~h}$ at $-80{ }^{\circ} \mathrm{C}$ in the presence of an intensifying screen.

\section{RESULTS}

\section{In silico analysis of the $S$. mutans gcrR gene}

GcrR, first described by Sato et al. (2000) and later renamed TarC (Idone et al., 2003) is an orthologue of the CovR regulator of S. pyogenes (Graham et al., 2002) and Streptococcus agalactiae (Jiang et al., 2005; Lamy et al., 2004), where it is found in association with its cognate CovS histidine kinase. In contrast, the $S$. mutans gcrR gene, not to be confused with vicR of the $S$. mutans vicRKX locus (Senadheera et al., 2005), for which orthologues have been characterized in S. pneumoniae (Wagner et al., 2002) and Bacillus subtilis (Szurmant et al., 2005), encodes a response regulator that is organized on the $S$. mutans chromosome as a monocistron, and as we demonstrated previously, is not cotranscribed with a cognate histidine kinase (Idone et al., 2003). Interestingly, a query of the Los Alamos Oral Pathogen database (http://www.oralgen.lanl.gov) with the S. mutans GcrR amino acid sequence revealed homologues in other bacterial pathogens that survive acid stress in the host environment. Specifically, the results of a BLASTP search demonstrated that GcrR shares $75 \%$ amino acid identity with the CovR response regulator of $S$. pyogenes, $64 \%$ identity with the EtaR response regulator of Ent. faecalis, and $57 \%$ identity with the LisR response regulator in L. monocytogenes. An analysis of the S. mutans gcrR promoter region with the MFold search engine (Workman et al., 2002) revealed stem-loop structures, to which SloR could potentially bind, although a recognizable consensus palindrome (AAATTAACTTGACTTAATTTTT) defined previously by Kitten et al. (2000) could not be confirmed given the low $\mathrm{G}+\mathrm{C}$ content of the S. mutans genome.

\section{Confirmation of $g c r R$ disruption in S. mutans GMS901}

Erythromycin-resistant transformants were screened for deletion of the $g c r R$ locus and replacement with ermAM as a result of double-crossover recombination. Genomic DNA was isolated from selected transformants and used as a template for PCR amplification with primers $g c r R \_P 1$ and gcrR_P4 (Fig. 1, Table 2). The resulting PCR amplicons were analysed by agarose gel electrophoresis, and their sizes were compared with those predicted following a successful allelic exchange event. Nucleotide sequencing of the purified amplicons with the same primer set confirmed disruption of the $g c r R$ coding sequence, and the resulting mutant was designated GMS901. Finally, total RNA from GMS901 was reverse-transcribed and quantified for $g c r R$ transcription in real-time qRT-PCR experiments, the results of which revealed gcrR expression that was like that of the RTcontrol $\left(C_{t}=31.11 \pm 0.3\right.$ and $29.18 \pm 0.67$, respectively $)$.

\section{S. mutans GMS901 is acid sensitive}

We conducted $S$. mutans growth determination experiments to monitor the aciduricity of the S. mutans sloR- (GMS584) and $g c r R$ - (GMS901) deficient mutants relative to their UA159 wild-type progenitor at physiological and acidic $\mathrm{pH}$. Results representative of six independent experiments are shown in Fig. 2. Importantly, we observed equal survivorship for all S. mutans strains following $24 \mathrm{~h}$ of growth at $\mathrm{pH} 5.0$ (data not shown). The growth rate of GMS901 at $\mathrm{pH} 7.5$ was comparable to that of the wild-type during midexponential phase (doubling times $\sim 60 \mathrm{~min}$ ), but was significantly compromised relative to the wild-type at pH 5.0 (Student's $t$ test; $P=0.024$ ). Specifically, the exponential-phase doubling time for GMS901 at $\mathrm{pH} 5.0$ was 30 min longer than that of UA159, and GMS901 ultimately attained a lower final resting culture density than wild-type $\left(\mathrm{OD}_{600} \sim 0.7\right.$ and $\sim 1.0$, respectively). GMS901 reached a lower resting culture density at $\mathrm{pH} 7.5$ as well, a result that we attribute to the clumping phenotype of the mutant when grown in broth culture. Finally, growth of $S$. mutans GMS584 at acidic $\mathrm{pH}$ was not significantly different from that of the wild-type, with doubling times of 146 and $135 \mathrm{~min}$, respectively. Taken together, these findings support the involvement of GcrR in the ability of $S$. mutans to withstand acid stress and indicate that defects in acid tolerance arise from $g c r R$ deficiency.

\section{The ATR is significantly impaired in S. mutans GMS901}

We examined the kinetics of acid killing for S. mutans UA159 and GMS901 adapted and unadapted cells that had 


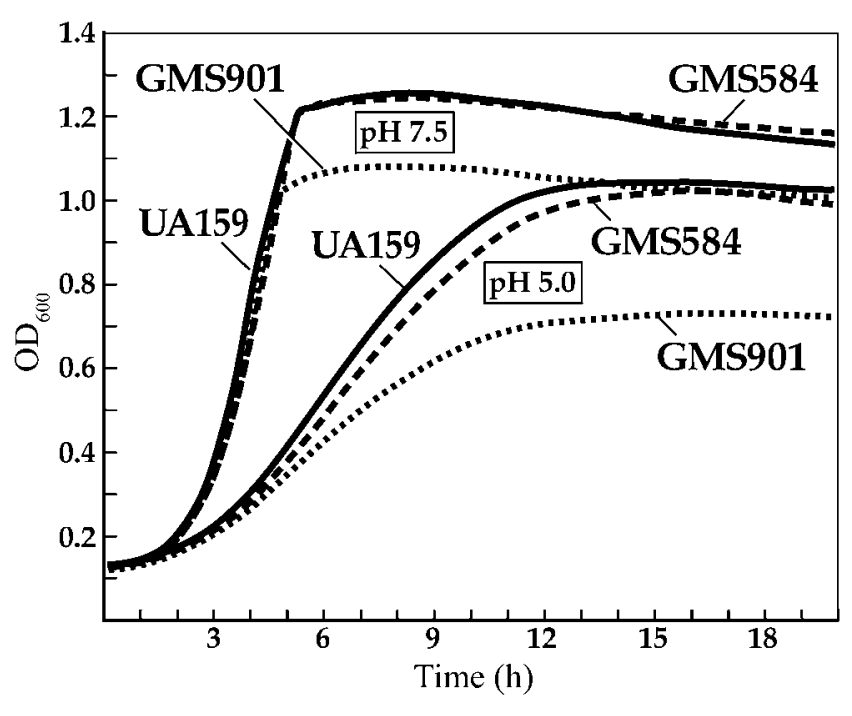

Fig. 2. S. mutans GMS901 is significantly more acid-sensitive than GMS584 and the UA159 wild-type progenitor. S. mutans UA159 (solid lines), GMS584 (dashed lines) and GMS901 (dotted lines) were grown in a rich THYE medium adjusted to $\mathrm{pH} 7.5$ or $\mathrm{pH} 5.0$, as described in Methods. Plate counts confirmed the viability of all strains during the stationary phase of growth at both pHs. S. mutans UA159, GMS584 and GMS901 demonstrate similar growth rates at $\mathrm{pH} 7.5$ with doubling times $\sim 60 \mathrm{~min}$. The lower final culture density for GMS901 at physiological $\mathrm{pH}$ may be attributed to the clumping phenotype of this mutant when grown in liquid culture. At pH 5.0, the growth of GMS901 was significantly compromised relative to both GMS584 and the wild-type ( $P=0.002$ and 0.024 , respectively). Specifically, the $\mathrm{pH}$ shift from 7.5 to 5.0 increased the doubling times for UA159, GMS584 and GMS901 by 77, 85 and $100 \mathrm{~min}$, respectively. Results representative of six independent experiments are shown.

been exposed to the killing $\mathrm{pH}$ of 3.5 for up to $3 \mathrm{~h}$. The results of a single representative experiment from a total of at least five independent experiments are expressed as percentage survival in Fig. 3(a). From these experiments we noted that 90 min of incubation at the killing $\mathrm{pH}$ was sufficient to reduce the number of unadapted wild-type and mutant survivors by 2-3 log units (Fig. 3a, filled symbols). In addition, we observed similar survivorship for GMS901 and UA159 unadapted cells after $3 \mathrm{~h}$ of exposure to $\mathrm{pH} 3.5$ (differing by only $0.05 \%$ ), indicating that the clumping phenotype of GMS901 has little if any impact on acid sensitivity following cellular deaggregation through a fine-gauge needle. Importantly, the survivorship we noted for adapted GMS901 cells differed from that of unadapted cells by less than $0.5 \log$ units after $3 \mathrm{~h}$ of exposure to the killing $\mathrm{pH}$, whereas adapted and unadapted wild-type cells differed by more than $2 \log$ units, with adapted cells demonstrating significantly greater survivorship (Student's $t$ test, $P<0.05$, Table 3 ). Taken together, these findings underscore the importance of GcrR as a modulator of the S. mutans ATR.

Disruption of the sloR ORF in S. mutans GMS584 did not significantly affect the viability of adapted cells after $3 \mathrm{~h}$ at the killing $\mathrm{pH}$ (Table 3), although taking the large variations between experiments into consideration, the results do show a trend that is consistent with a role for SloR in the S. mutans response to acid stress.

\section{Complementation analyses}

Complementation of the sloR mutation in S. mutans GMS584 was reported previously by Rolerson et al. (2006). In the present study, in silico analysis of the $S$. mutans UA159 genome revealed no ORFs within $350 \mathrm{bp}$ of the gcrR coding sequence on either DNA strand, making polar effects resulting from the insertion-deletion mutation in GMS901 unlikely. Nevertheless, we complemented the gcrR mutation on the GMS901 chromosome in trans to confirm specific involvement of GcrR in S. mutans acid tolerance. To this end, we performed growth determination assays as described in Methods with S. mutans UA159, GMS901 and the pDD1-containing complemented mutant GMS902-3. We observed GMS902-3 exponential-phase growth that was intermediate between that of the GMS901 mutant and the UA159 wild-type strain when grown in THYE pH 5.0 (data not shown). In addition, the results of acid-challenge experiments (Fig. 3b) reveal that $26 \%$ of adapted GMS9023 cells survived a $3 \mathrm{~h}$ exposure to the killing $\mathrm{pH}$, whereas only $2.25 \%$ of unadapted GMS902-3 cells survived this acid challenge. These findings support rescue of the ATR defect in the GMS902-3 complemented strain (Fig. 3c). While the clumping phenotype of GMS902-3 was alleviated somewhat by complementation, it was not 'fixed', as determined by phase-contrast microscopy (data not shown). The persistence of cell clumps combined with restoration of the ATR in GMS902-3 supports a complementation effect that derives from $g c r R$ expression in trans rather than from cell dispersal. Finally, we observed unadapted GMS902-3 cells that were considerably more acid-resistant than unadapted wild-type cells (Fig. 3b), a result that we attribute to the presence of multiple copies of the $g c r R$ transcript in the complemented strain.

\section{Expression of $\operatorname{gcr} \boldsymbol{R}$ is not responsive to acidic pH}

To determine whether $S$. mutans $g c r R$ expression is acidresponsive, we performed three independent real-time qRT-PCR experiments with cDNAs that we isolated from S. mutans UA159 mid-exponential phase cells exposed to physiological $(\mathrm{pH} 7.5)$ or acidic $(\mathrm{pH}$ 5.0) conditions for $2 \mathrm{~h}$. The results of these experiments, each performed in triplicate, revealed no significant differences in $g c r R$ expression at either $\mathrm{pH}$, indicating that $\mathrm{gcrR}$ expression is not acid-responsive at the level of transcription (mean DNA copy number $=2.4 \times 10^{7}$ and $1.8 \times 10^{7}$ at $\mathrm{pH} 7.5$ and 5.0, respectively). 
(a)

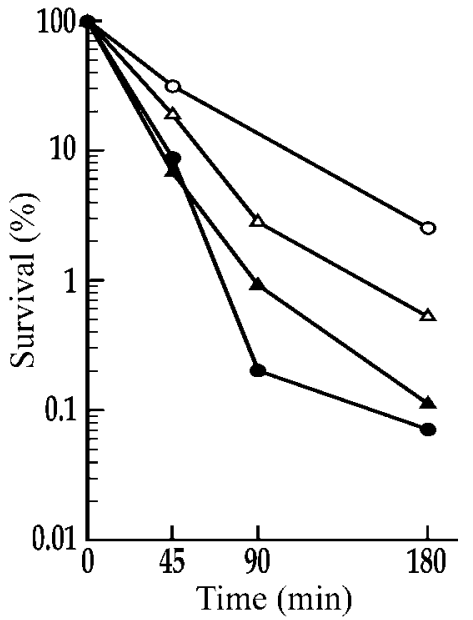

(b)

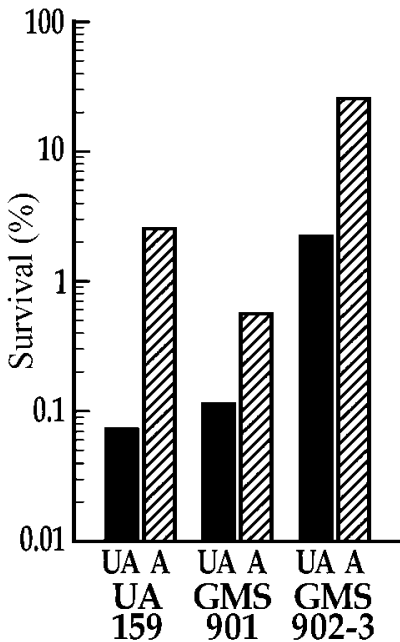

(c)

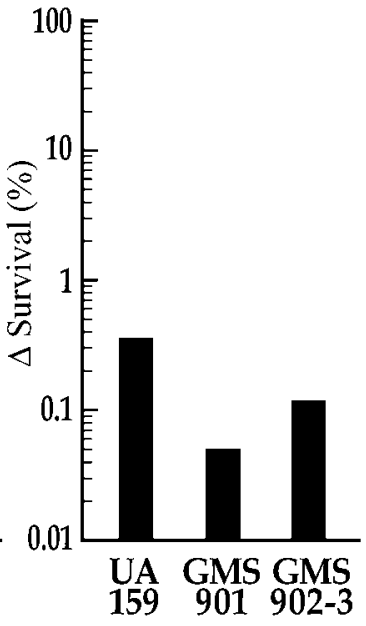

Fig. 3. The $S$. mutans ATR is significantly compromised in GMS901 relative to the wild-type UA159 progenitor strain. S. mutans UA159 and GMS901 cells were grown to mid-exponential phase in THYE, as described in Methods, and harvested by centrifugation, and this was followed by resuspension and de-aggregation in fresh THYE $\mathrm{pH} 7.5$ (unadapted) or $\mathrm{pH} 5.0$ (adapted). The cells were incubated under these conditions at $37{ }^{\circ} \mathrm{C}$ and $5 \% \mathrm{CO}_{2}$ for $2 \mathrm{~h}$ before exposure to the killing $\mathrm{pH}$ of 3.5 for up to $3 \mathrm{~h}$. Importantly, there was no change in cell density $\left(\mathrm{OD}_{600}\right)$ for any of the $S$. mutans cultures during the $2 \mathrm{~h}$ incubation period. Following acid challenge at $\mathrm{pH} 3.5$ for $0,45,90$ and $180 \mathrm{~min}$, the cells were plated onto THYE agar and incubated at $37{ }^{\circ} \mathrm{C}$ and $5 \% \mathrm{CO}_{2}$ for $48 \mathrm{~h}$. (a) The results of viable plate counting are expressed as the percentage of viable cells (in c.f.u. $\mathrm{ml}^{-1}$ ) at each time point relative to viable cells (in c.f.u. $\mathrm{ml}^{-1}$ ) present at $t=0$. The survival of GMS901 adapted cells $(\triangle)$ after $3 \mathrm{~h}$ at the killing $\mathrm{pH}$ differed from that of unadapted cells $(\boldsymbol{\Delta})$ by 0.5 log units, whereas that of adapted and unadapted wild-type cells ( $\bigcirc$ and $\bullet$, respectively) differed by at least two orders of magnitude, suggesting a defective ATR in GMS901. The results of a single representative experiment from a total of at least five independent experiments are shown. (b) Percentage survivorship for adapted (A, hatched bars) and unadapted (UA, black bars) UA159, GMS901 and complemented GMS902-3 cells after a $3 \mathrm{~h}$ exposure to the killing $\mathrm{pH}$. The ATR defect was rescued in GMS902-3 by at least 1 log unit, despite the persistence of clumping in this strain. (c) The efficiency of the ATR in each strain is expressed as the difference in survivorship between adapted and unadapted cells. The complemented mutant demonstrates an ATR that is intermediate between that of the wild-type UA159 strain and the GMS901 gcrR-deficient mutant, supporting gcrR complementation of the ATR defect in trans.

\section{GcrR is subject to SloR metalloregulation in S. mutans}

Transcription of the $S$. mutans gcrR gene was unaffected by $\mathrm{pH}$, despite our hypothesis that GcrR is involved in modulating the S. mutans ATR. This led us to investigate other potential mechanisms of $g c r R$ control that may affect, but otherwise be unrelated to, the ATR. Interestingly, microarray experiments that we had performed previously with RNAs isolated from S. mutans UA159 and the GMS584 sloR-deficient mutant indicated that $g c r R$ expression was down-regulated in the mutant by more than

Table 3. Acid-adaptive response for S. mutans UA159 and its isogenic derivatives

\begin{tabular}{|lccc|}
\hline S. mutans strain & Growth $\mathbf{~ H ~}$ & Survival (\%) after $\mathbf{3} \mathbf{h}^{*}$ & Student's $\boldsymbol{t}$ test $\dagger$ \\
\hline UA159 & 7.5 & $7.3 \times 10^{-2}\left( \pm 1.1 \times 10^{-1}\right)$ & $P<0.05$ \\
& 5.0 & $260 \times 10^{-2}\left( \pm 41 \times 10^{-1}\right)$ & NS \\
GMS901 & 7.5 & $1.2 \times 10^{-1}\left( \pm 0.5 \times 10^{-1}\right)$ & \\
& 5.0 & $5.3 \times 10^{-1}\left( \pm 1.6 \times 10^{-1}\right)$ & NS \\
GMS584 & 7.5 & $1.1 \times 10^{-1}\left( \pm 0.1 \times 10^{-1}\right)$ & \\
& 5.0 & $7.6 \times 10^{-1}\left( \pm 2.7 \times 10^{-1}\right)$ & \\
\end{tabular}

${ }^{\star}$ Mean $( \pm \mathrm{SD})$.

$\dagger$ NS, Non-significant. 
twofold when cells were grown in a nutrient-replete SDM (data not shown). These results are consistent with $g c r R$ expression that is subject to SloR control. We validated SloR modulation of $g c r R$ expression in real-time qRT-PCR experiments, where we observed fourfold less $g c r R$ mRNA in GMS584 relative to UA159 (DNA copy number $=3.4 \times 10^{6}$ and $1.5 \times 10^{7}$, respectively) for cells grown in nutrient-replete SDM. Taken collectively, these findings led us to suspect that $S$. mutans gcrR expression might be responsive to manganese. Additional microarray experiments that we had performed with RNAs isolated from UA159 cells grown in a manganese-depleted $(0.1 \mu \mathrm{M}$ $\left.\mathrm{MnCl}_{2}\right)$ versus a manganese-replete $\left(10 \mu \mathrm{M} \mathrm{MnCl}_{2}\right) \mathrm{SDM}$ supported $g c r R$ expression being manganese-responsive, and validation of these results in real-time qRT-PCR experiments revealed that $g c r R$ transcription was upregulated more than threefold at the lower manganese concentration (DNA copy number $=1.7 \times 10^{6}$ at $0.1 \mu \mathrm{M}$ and $4.9 \times 10^{5}$ at $\left.10 \mu \mathrm{M}\right)$. These findings support induction of $S$. mutans $g c r R$ transcription under conditions of micronutrient deprivation, and are consistent with $g c r R$ regulation that is stressresponsive and subject to SloR and/or manganese control.

\section{S. mutans sloR expression is acid-responsive}

To better describe SloR metalloregulation and its impact on GcrR as part of a general stress response in S. mutans, we set out to determine whether sloR expression, already known to be metal ion-responsive (Kitten et al., 2000; Paik et al., 2003), might also be sensitive to acidic $\mathrm{pH}$. To this end, we monitored sloR transcription in real-time qRTPCR experiments with cDNAs derived from S. mutans UA159 cells grown in THYE $\mathrm{pH} 7.5$ or $\mathrm{pH}$ 5.0. The results of these studies support sloR transcription that is increased sixfold at acidic $\mathrm{pH}$ (DNA copy number $=1.2 \times 10^{8}$ at $\mathrm{pH} 7.5$ and $6.8 \times 10^{8}$ at $\mathrm{pH} 5.0$ ), indicating that SloR is indeed responsive to acid stress.

\section{SloR binds upstream of the S. mutans gcrR gene}

The results of gel mobility shift assays support direct SloR binding to the $g c r R$ promoter region. That is, migration of the $g c r R$ promoter fragment was hindered in the presence of the SloR-MBP fusion protein, but not when the EDTA metal ion chelator was added to the reaction mixture. The band shift was rescued when $\mathrm{MnCl}_{2}$ was added to the EDTA-containing reaction mixture, however, supporting the hypothesis that SloR binding at this region is manganese-dependent (Fig. 4). Abrogation of the band shift with increasing amounts of cold $g c r R$ promoter DNA supports the suggestion that SloR-MBP binding is specific to the $g c r R$ promoter region, and the absence of a shift when pure MBP was present in the reaction mixture supports the involvement of the SloR portion of the fusion

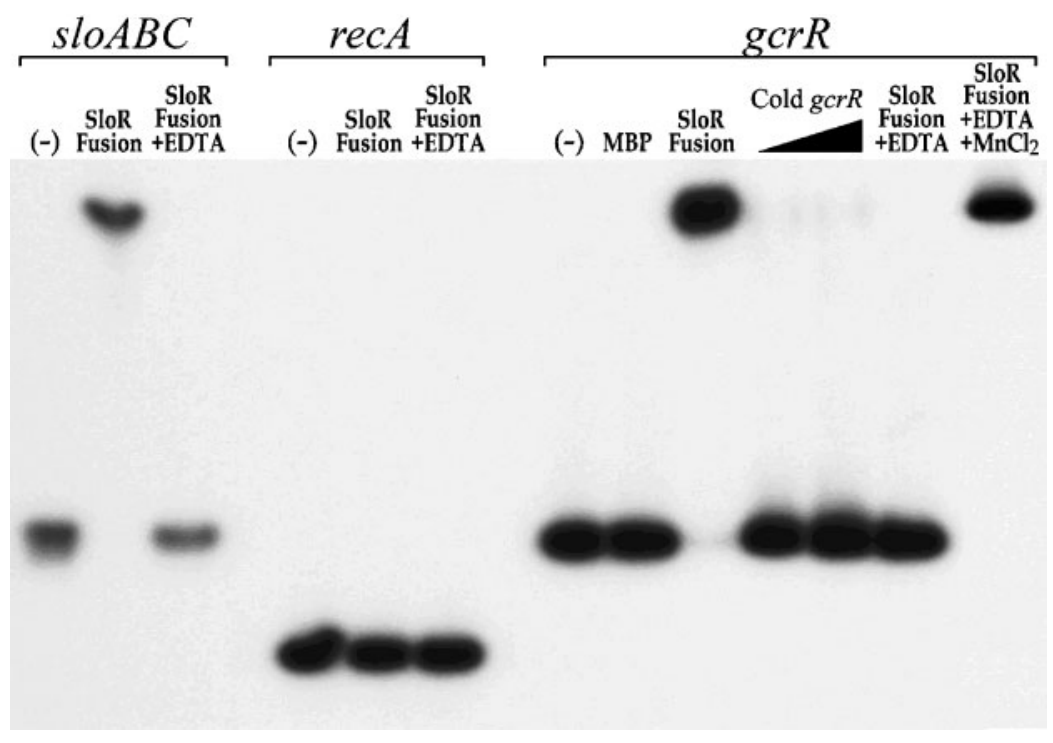

Fig. 4. The $S$. mutans SloR protein binds directly to the $g c r R$ promoter region. The results of gel mobility shift assays confirm direct binding of SloR to the gcrR promoter region. Specifically, the $S$. mutans sloABC (310 bp), recA (212 bp) and gcrR (308 bp) promoter regions were PCR-amplified as described in Methods and end-labelled with $\left[\gamma_{-}{ }^{32} \mathrm{P}\right]$ ATP in the presence of T4 polynucleotide kinase. The resulting radiolabelled amplicons ( 17 ng) were incorporated into separate reaction mixtures containing $8.5 \mu \mathrm{M}$ purified MBP or SloR-MBP fusion protein. Competition assays with excess cold $\mathrm{gcr} R$ DNA were also performed to address the binding specificity of SloR to the $g c r R$ promoter fragment. Other controls included reaction mixtures without any added protein $(-)$, supplemented with EDTA, or supplemented with both EDTA and $\mathrm{MnCl}_{2}$. Collectively, the results indicate that the SloR portion of the fusion protein binds directly and specifically to the sloABC and gcrR promoter regions, and that the SloR-DNA binding interaction is manganese-dependent. The $\operatorname{rec} A$ promoter region, devoid of recognizable SloR binding palindromes, was included in these studies as a negative control. 
protein in binding to DNA. An upward band shift was similarly noted for the $s l o A B C$ promoter region, which harbours a 'classical' SloR-binding palindrome, whereas no shift was evident for the recA promoter region, which is devoid of recognizable SloR palindromes. The affinity of the fusion protein for $g c r R$ DNA binding appears to be even greater than that of the sloABC DNA control, based on the relatively robust intensity of the $g c r R$ promoter fragment on the autoradiogram and comparable specific activities for the end-labelling reactions.

\section{GcrR modulates expression of known contributors to the S. mutans ATR}

To validate the importance of GcrR as a regulator of the $S$. mutans ATR, we compared the expression of several known ATR genes in UA159 and GMS901 cells that had been resuspended in THYE pH 5.0 for $2 \mathrm{~h}$. The results of these real-time qRT-PCR experiments support GcrR as a regulator of $\mathrm{ffh}$, which encodes a bacterial signal recognition particle that is linked to the ATR (Gutierrez et al., 1999), and of atpA/E, which encode the functional and membrane-spanning subunits of the $S$. mutans protontranslocating $\mathrm{F}_{0}$-ATPase. Specifically, the transcription of ffh was down-regulated in GMS901 relative to UA159 by 1.6-fold (DNA copy number $=5.5 \times 10^{6}$ and $8.5 \times 10^{6}$, respectively), and atpE expression was likewise repressed in the gcrR-deficient mutant by 2.5-fold (DNA copy number $=2.4 \times 10^{8}$ in GMS901 and $5.7 \times 10^{8}$ in UA159). These findings support a direct relationship between GcrR and the activation of genes whose products contribute to mechanisms that maintain internal $\mathrm{pH}$ homeostasis in $S$. mutans.

\section{S. mutans ATR genes are SloR- and manganese- responsive}

To confirm a role for GcrR as a regulator of the $S$. mutans ATR that acts downstream of SloR metalloregulation, we monitored atpA/E expression for SloR- and manganeseresponsiveness in real-time qRT-PCR studies. Specifically, we observed atp $A / E$ expression that was upregulated 3.6-fold in an SDM containing $0.1 \mu \mathrm{M}$ manganese (DNA copy number $=8.7 \times 10^{6}$ ) as compared to the same medium containing $10 \mu \mathrm{M}$ manganese (DNA copy number $\left.=2.4 \times 10^{6}\right)$. Moreover, the expression of atpA/E was decreased threefold in GMS584 relative to UA159 (DNA copy number $=1.2 \times 10^{8}$ and $3.1 \times 10^{8}$, respectively). Taken together, these findings support an $S$. mutans ATR that is SloR-modulated and affected by growth-limiting manganese.

\section{DISCUSSION}

This study presents evidence to support GcrR modulation of the $S$. mutans ATR that expands on its functional role during cariogenesis. Our previous report (Idone et al., 2003) described the involvement of GcrR in S. mutans sucrose-dependent adherence owing to its effect on expression of the glucosyltransferase-D $(g t f D)$ and glucan binding protein $\mathrm{C}(g b p C)$ genes. In those studies we described a UA130-derived gcrR-deficient mutant, designated GMS900, which formed aberrant biofilms and was hypocariogenic in a germ-free rat model. These findings implicate GcrR as a major modulator of $S$. mutans virulence, yet the molecular mechanisms that regulate its expression are poorly understood. In this study, we describe the impact of GcrR on S. mutans acid tolerance and investigate its regulation as part of a stress response involving SloR metalloregulation.

The byproducts, especially sucrose, of dietary carbohydrate metabolism by $S$. mutans and other acidogenic constituents of the oral microflora can yield a plaque $\mathrm{pH}$ as low as 3.0 (Jensen et al., 1982; Loesche, 1986). S. mutans can adapt to this killing $\mathrm{pH}$ by modulating an arsenal of genes that contribute to its ATR (Cotter \& Hill, 2003). Specifically, when conditions of acid stress $(\mathrm{pH} \sim 5.0)$ prevail in the plaque environment, genes whose products facilitate DNA repair (uvrA), modulate cytoplasmic $\mathrm{pH}($ atpE) and foster protein secretion (ffh) are induced (Fozo \& Quivey, 2004; Hanna et al., 2001; Kuhnert et al., 2004). Collectively, these and other constituents of the ATR promote S. mutans survival at acidic $\mathrm{pH}$, and their regulation is likely to be complex, involving mechanisms of control at the transcriptional and post-transcriptional levels.

Other pathogens that confront acid conditions in the host environment during infection include $S$. pyogenes, Ent. faecalis and L. monocytogenes, all of which harbour homologues of the $S$. mutans GcrR protein (Arikado et al., 1999; Farber \& Peterkin, 1991; Flahaut et al., 1996b; Mead et al., 1999). Namely, CovR, EtaR and LisR each form part of a two-component signal transduction system in their respective micro-organisms, in which they have been shown to promote an ATR (Cotter et al., 1999; Fozo et al., 2007; Teng et al., 2002). To reveal a putative role for the GcrR response regulator in the ability of $S$. mutans to adapt to and survive acid stress, we generated an insertiondeletion mutation in the $S$. mutans $g c r R$ gene on the fully sequenced $S$. mutans UA159 chromosome and analysed the resulting mutant, GMS901, in acid-challenge experiments. From these experiments we noted growth rates for UA159 and GMS901 that were comparable in a rich THYE pH 7.5 medium but that differed considerably at pH 5.0 (Fig. 2). At the latter pH, GMS901 displayed a prolonged lag phase and a decreased final resting culture density relative to the wild-type, consistent with GMS901 growth that is acidsensitive, and implicating GcrR in S. mutans aciduricity.

We successfully induced an $S$. mutans ATR in the wild-type UA159 strain, since the survival of unadapted and adapted cells differed by more than $2 \log$ units after a $3 \mathrm{~h}$ exposure to the killing $\mathrm{pH}$ (Fig. 3a). In contrast, the survivorship of GMS901 unadapted and adapted cells differed by $0.5 \mathrm{log}$ units, thereby implicating GcrR in the S. mutans ATR. Importantly, GMS901 and UA159 cells appeared to be 
equally sensitive to acid after $3 \mathrm{~h}$ at the killing $\mathrm{pH}$ (Fig. 3a, closed symbols), despite the propensity of GMS901 to aggregate in liquid culture. We therefore attribute attenuation of the ATR in GMS901 to the $g c r R$ defect in this strain and not to its clumping behaviour that could otherwise protect cells from the effects of low-pH environments. Lending further support to GcrR involvement in the $S$. mutans ATR is the increased survivorship we noted for the adapted GMS902-3 complemented strain after $3 \mathrm{~h}$ at the killing $\mathrm{pH}$. Specifically, the survival of these cells was more than 10-fold greater than that of unadapted GMS902-3 cells (Fig. 3b), despite the persistence of clumping in this strain (i.e. the clumping phenotype of GMS902-3 was alleviated, but not completely 'fixed' by complementation). Collectively, these findings support rescue of the ATR defect by $g c r R$ complementation in trans, and substantiate the relationship between GcrR and regulation of the S. mutans ATR.

A response as complex as the ATR likely involves a repertoire of $S$. mutans genes that are GcrR-responsive. In this report we describe a significant effect of GcrR on $S$. mutans ffh and atpA/E transcription, the products of which contribute significantly to the $S$. mutans ATR (Gutierrez et al., 1999; Crowley et al., 2004). Specifically, the ffh gene, which is part of the sat operon on the S. mutans chromosome, encodes a eukaryotic signal-recognition particle homologue that has been implicated in acid tolerance. A mutation in the ffh coding sequence gives rise to mutants that are strongly acid-sensitive (Gutierrez et al., 1999) and severely compromised in $\mathrm{F}_{0}$-ATPase activity at physiological and acidic pH (Crowley et al., 2004). Previous work has correlated $S$. mutans acid adaptation with increased proton-extruding $\mathrm{F}_{0}$-ATPase activity, and the latter correlates with increased transcription of the $\mathrm{F}_{0^{-}}$ ATPase operon (Hamilton \& Buckley, 1991). The $\mathrm{F}_{0^{-}}$ ATPase operon, which comprises the atpEBFHAGDC genes, is cotranscribed to give rise to the functional and membrane-spanning domains of the proton-translocating $\mathrm{F}_{0}$-ATPase. In the present study we describe a decrease in GMS901 ffh transcription that coordinates with a more than twofold decrease in atp $A / E$ expression, supporting an $S$. mutans ATR that is subject to GcrR control.

The results of transcription profiling experiments support atpA/E and $g c r R$ expression that is both SloR-dependent and affected by growth-limiting manganese, consistent with a model that implicates GcrR control as part of a general stress response in $S$. mutans. Constitutive expression of the $S$. mutans $g c r R$ gene under both physiological $(\mathrm{pH}$ 7.5) and acidic ( $\mathrm{pH}$ 5.0) conditions further supports multiple mechanisms of $\mathrm{gcrR}$ control that can affect the ATR. Taken together, our experimental findings support a direct interaction between SloR and GcrR that is stressresponsive but not directly related to the ATR. Specifically, GcrR and the ATR genes that are subject to its control are de-repressed under conditions of manganese deprivation when formation of SloR-Mn repressor complexes is restricted. In contrast, $g c r R$ transcription is repressed by
SloR-Mn in manganese-replete environments that are less stressful for the bacteria. These findings demonstrate a role for manganese as a general stress mediator of $S$. mutans $g c r R$ expression. Lending further support to $g c r R$ regulation as part of a general stress response is the induction of $\mathrm{gcrR}$ expression upon exposure of $S$. mutans to serine hydroxymate, an amino acid analogue that induces growth arrest (Robert Burne, Department of Oral Biology, University of Florida, Gainesville, personal communication). In summary, these findings support the existence of a link between SloR-Mn and GcrR in the S. mutans response to acid stress.

Although this report presents evidence to support direct regulation of GcrR by SloR, cross-communication between GcrR and contributors to S. mutans acid tolerance is likely to be more complex. Future experiments will investigate the mode of action of manganese in $g c r R$ repression and reveal downstream target genes of GcrR so that the mechanisms that control S. mutans adaptation to acidic $\mathrm{pH}$ can be revealed. An improved understanding of this and other gene networks in this oral pathogen could give rise to novel therapies aimed at alleviating caries and their complications.

\section{ACKNOWLEDGEMENTS}

This research was supported by National Institutes of Health (NIH) grant R01 DE014711 to G.A.S., the Vermont Genetics Network through grant number P20 RR16462 from the Institutional Development Award Network of Biomedical Research Excellence (INBRE) Program of the National Center for Research Resources, a component of the NIH, and the Middlebury College Department of Biology. We wish to thank Jeff Bond at the University of Vermont for assistance with the analysis and interpretation of the microarray data, Frank Spatafora for technical assistance, and Gary Nelson for figure preparation.

\section{REFERENCES}

Arikado, E., Ishihara, H., Ehara, T., Shibata, C., Saito, H., Kakegawa, T., Igarashi, K. \& Kobayashi, H. (1999). Enzyme level of enterococcal $\mathrm{F}_{1} \mathrm{~F}_{0^{-}}$ ATPase is regulated by $\mathrm{pH}$ at the step of assembly. Eur J Biochem 259, 262-268.

Cotter, P. D. \& Hill, C. (2003). Surviving the acid test: responses of Gram-positive bacteria to low pH. Microbiol Mol Biol Rev 67, 429-453.

Cotter, P. D., Emerson, N., Gahan, C. G. \& Hill, C. (1999). Identification and disruption of lisRK, a genetic locus encoding a two-component signal transduction system involved in stress tolerance and virulence in Listeria monocytogenes. J Bacteriol 181, 6840-6843.

Crowley, P. J., Svensater, G., Snoep, J. L., Bleiweis, A. S. \& Brady, L. J. (2004). An ffh mutant of Streptococcus mutans is viable and able to physiologically adapt to low $\mathrm{pH}$ in continuous culture. FEMS Microbiol Lett 234, 315-324.

Dalton, T. L. \& Scott, J. R. (2004). CovS inactivates CovR and is required for growth under conditions of general stress in Streptococcus pyogenes. J Bacteriol 186, 3928-3937.

Farber, J. M. \& Peterkin, P. I. (1991). Listeria monocytogenes, a foodborne pathogen. Microbiol Rev 55, 476-511. 
Ferreira, A., O'Byrne, C. P. \& Boor, K. J. (2001). Role of $\sigma^{\mathrm{B}}$ in heat, ethanol, acid, and oxidative stress resistance and during carbon starvation in Listeria monocytogenes. Appl Environ Microbiol 67, 4454-4457.

Flahaut, S., Frere, J., Boutibonnes, P. \& Auffray, Y. (1996a). Comparison of the bile salts and sodium dodecyl sulfate stress responses in Enterococcus faecalis. Appl Environ Microbiol 62, 2416-2420.

Flahaut, S., Hartke, A., Giard, J. C., Benachour, A., Boutibonnes, P. \& Auffray, Y. (1996b). Relationship between stress response toward bile salts, acid and heat treatment in Enterococcus faecalis. FEMS Microbiol Lett 138, 49-54.

Foster, J. W. \& Hall, H. K. (1990). Adaptive acidification tolerance response of Salmonella typhimurium. J Bacteriol 172, 771-778.

Fozo, E. M. \& Quivey, R. G., Jr (2004). The fabM gene product of Streptococcus mutans is responsible for the synthesis of monounsaturated fatty acids and is necessary for survival at low $\mathrm{pH}$. J Bacteriol 186, 4152-4158.

Fozo, E. M., Scott-Anne, K., Koo, H. \& Quivey, R. G., Jr (2007). Role of unsaturated fatty acid biosynthesis in virulence of Streptococcus mutans. Infect Immun 75, 1537-1539.

Graham, M. R., Smmot, L. M., Lux Migliaccio, C. A., Virtaneva, K., Sturdevant, D. E., Porcella, S. F., Federle, M. J., Adams, G. J., Scott, J. R. \& Musser, J. M. (2002). Virulence control in group A Streptococcus by a two-component gene regulatory system: global expression profiling and in vivo infection modeling. Proc Natl Acad Sci U S A 99, 13855-13860.

Griswold, A. R., Jameson-Lee, M. \& Burne, R. A. (2006). Regulation and physiologic significance of the agmatine deiminase system of Streptococcus mutans UA159. J Bacteriol 188, 834-841.

Gutierrez, J. A., Crowley, P. J., Cvitkovitch, D. G., Brady, L. J., Hamilton, I. R., Hillman, J. D. \& Bleiweis, A. S. (1999). Streptococcus mutans $\mathrm{ffh}$, a gene encoding a homologue of the $54 \mathrm{kDa}$ subunit of the signal recognition particle, is involved in resistance to acid stress. Microbiology 145, 357-366.

Hamilton, I. R. \& Buckley, N. D. (1991). Adaptation by Streptococcus mutans to acid tolerance. Oral Microbiol Immunol 6, 65-71.

Hamilton, I. R. \& Svensater, G. (1998). Acid-regulated proteins induced by Streptococcus mutans and other oral bacteria during acid shock. Oral Microbiol Immunol 13, 292-300.

Hanna, M. N., Ferguson, R. J. \& Cvitkovitch, D. G. (2001). uvrA is an acid-inducible gene involved in the adaptive response to low $\mathrm{pH}$ in Streptococcus mutans. J Bacteriol 183, 5964-5973.

Idone, V., Brendtro, S., Gillespie, R., Kocaj, S., Peterson, E., Rendi, M., Warren, W., Mickalek, S., Krastel, K. \& other authors (2003). Effect of an orphan response regulator on $S$. mutans sucrose-dependent adherence and cariogenesis. Infect Immun 71, 4351-4360.

Jayaraman, G. C., Penders, J. E. \& Burne, R. A. (1997). Transcriptional analysis of the Streptococcus mutans hrcA, grpE and $d n a K$ genes and regulation of expression in response to heat shock and environmental acidification. Mol Microbiol 25, 329-341.

Jensen, M. E., Polansky, P. J. \& Schachtele, C. F. (1982). Plaque sampling and telemetry for monitoring acid production on human buccal tooth surfaces. Arch Oral Biol 27, 21-31.

Jiang, S.-M., Cieslewica, M. J., Kasper, D. L. \& Wessels, M. R. (2005). Regulation of virulence by a two-component system in group $\mathrm{B}$ Streptococcus. J Bacteriol 187, 1105-1113.

Kitten, T., Munro, C. L., Michalek, S. M. \& Macrina, F. L. (2000). Genetic characterization of a Streptococcus mutans LraI family operon and role in virulence. Infect Immun 68, 4441-4451.

Korithoski, B., Krastel, K. \& Cvitkovitch, D. G. (2005). Transport and metabolism of citrate by Streptococcus mutans. J Bacteriol 187, $4451-4456$.
Kuhnert, W. L., Zheng, G., Faustoferri, R. C. \& Quivey, R. G., Jr (2004). The F-ATPase operon promoter of Streptococcus mutans is transcriptionally regulated in response to external pH. J Bacteriol 186, 8524-8528.

Lamy, M. C., Zouine, M., Fert, J., Vergassola, M., Couve, E., Pellegrini, E., Glaser, P., Kunst, F., Msadek, T. \& other authors (2004). CovS/CovR of group B streptococcus: a two-component global regulatory system involved in virulence. Mol Microbiol 54, 1250-1268.

Lau, P. C., Sung, C. K., Lee, J. H., Morrison, D. A. \& Cvitkovitch, D. G. (2002). PCR ligation mutagenesis in transformable streptococci: application and efficiency. J Microbiol Methods 49, 193-205.

Leblanc, D. J. \& Lee, L. N. (1979). Rapid screening procedure for detection of plasmids in streptococci. J Bacteriol 140, 1112-1115.

Lemos, J. A., Chen, Y. Y. \& Burne, R. A. (2001). Genetic and physiologic analysis of the groE operon and role of the HrcA repressor in stress gene regulation and acid tolerance in Streptococcus mutans. J Bacteriol 183, 6074-6084.

Len, A. C. L., Harty, D. W. S. \& Jacques, N. A. (2004a). Stress responsive proteins are upregulated in Streptococcus mutans during acid tolerance. Microbiology 150, 1339-1351.

Len, A. C. L., Harty, D. W. S. \& Jacques, N. A. (2004b). Proteome analysis of Streptococcus mutans metabolic phenotype during acid tolerance. Microbiology 150, 1353-1366.

Li, Y. H., Hanna, M. N., Svensater, G., Ellen, R. P. \& Cvitkovitch, D. G. (2001a). Cell density modulates acid adaptation in Streptococcus mutans: implications for survival in biofilms. J Bacteriol 183, 6875-6884.

Li, Y. H., Lau, P. C., Lee, J. H., Ellen, R. P. \& Cvitkovitch, D. G. (2001b). Natural genetic transformation of Streptococcus mutans growing in biofilms. J Bacteriol 183, 897-908.

Li, Y. H., Lau, P. C., Tang, N., Svensater, G., Ellen, R. P. \& Cvitkovitch, D. G. (2002). Novel two-component regulatory system involved in biofilm formation and acid resistance in Streptococcus mutans. J Bacteriol 184, 6333-6342.

Loesche, W. J. (1986). Role of Streptococcus mutans in human dental decay. Microbiol Rev 50, 353-380.

Macrina, F. L., Tobian, J. A., Jones, K. R., Evans, R. P. \& Clewell, D. B. (1982). A cloning vector able to replicate in Escherichia coli and Streptococcus sanguis. Gene 19, 345-353.

Mead, P. S., Slutsker, L., Dietz, V., McCaig, L. F., Bresee, J. S., Shapiro, C., Griffin, P. M. \& Tauxe, R. V. (1999). Food-related illness and death in the United States. Emerg Infect Dis 5, 607-625.

Nascimento, M. M., Lemos, J. A., Abranches, J., Goncalves, R. B. \& Burne, R. A. (2004). Adaptive acid tolerance response of Streptococcus sobrinus. J Bacteriol 186, 6383-6390.

Paik, S., Brown, A., Munro, C. L., Cornelissen, C. N. \& Kitten, T. (2003). The sloABCR operon of Streptococcus mutans encodes an Mn and $\mathrm{Fe}$ transport system required for endocarditis virulence and its Mn-dependent repressor. J Bacteriol 185, 5967-5975.

Rolerson, E., Swick, A., Newlon, L., Palmer, C., Pan, Y., Keeshan, B. \& Spatafora, G. (2006). The SloR/Dlg metalloregulator modulates Streptococcus mutans virulence gene expression. J Bacteriol 188, 5033-5044.

Sambrook, J., Fritsch, E. F. \& Maniatis, T. (1989). Molecular Cloning: a Laboratory Manual, 2nd edn. Cold Spring Harbor, NY: Cold Spring Harbor Laboratory.

Sato, Y., Yamamoto, Y. \& Kizaki, H. (2000). Construction of regionspecific partial duplication mutants (merodiploid mutants) to identify the regulatory gene for the glucan-binding protein $\mathrm{C}$ gene in vivo in Streptococcus mutans. FEMS Microbiol Lett 186, 187-191.

Senadheera, M. D., Guggenheim, B., Spatafora, G. A., Yi-Chen, C. H., Choi, J., Hung, D. C. I., Treglown, J. S., Goodman, S. D., Ellen, R. P. \& 
Cvitkovitch, D. G. (2005). A VickRK signal transduction system in Streptococcus mutans affects $g t f B C D, g b p B$, and $f t f$ expression, biofilm formation, and genetic competence development. J Bacteriol 187, 4064-4076.

Smith, R. S. (2001). Naturally Occurring Hazards. Article prepared for World Water Day, March 22 2001. Geneva: World Health Organization. http://www.worldwaterday.org/2001/thematic/natural.html

Szurmant, H., Nelson, K., Kim, E.-J., Perego, M. \& Hoch, J. A. (2005). $\mathrm{YycH}$ regulates the activity of the essential YycFG two component system in Bacillus subtilis. J Bacteriol 187, 5419-5426.

Tao, X., Boyd, J. \& Murphy, J. R. (1992). Specific binding of the diphtheria tox regulatory element DtxR to the tox operator requires divalent heavy metal ions and a 9-base-pair interrupted palindromic sequence. Proc Natl Acad Sci U S A 89, 5897-5901.

Teng, F., Wang, L., Singh, K. V., Murray, B. E. \& Weinstock, G. M. (2002). Involvement of PhoP-PhoS homologs in Enterococcus faecalis virulence. Infect Immun 70, 1991-1996.
US Department of Health and Human Services (2003). National Call to Action to Promote Oral Health. NIH publication number 035303. Rockville, MD: US Department of Health and Human Services, Public Health Service, National Institutes of Health, National Institute of Dental and Craniofacial Research.

Wagner, C., de Saizieu, A., Schonfeld, H.-J., Kamber, M., Lange, R., Thompson, C. J. \& Page, M. G. (2002). Genetic analysis and functional characterization of the Streptococcus pneumoniae vic operon. Infect Immun 70, 6121-6128.

Workman, C., Jensen, L. J., Jarmer, H., Berka, R., Gautier, L., Nielser, H. B., Saxild, H. H., Nielsen, C., Brunak, S. \& Knudsen, S. (2002). A new non-linear normalization method for reducing variability in DNA microarray experiments. Genome Biol 3, research00480048.16 .

Edited by: M. Kilian 